\title{
Multi-functional self-assembly nanoparticles originating from small molecule natural product for oral insulin delivery through modulating tight junctions
}

Xiaohui Jia ${ }^{\dagger}$, Zhihua Yuan ${ }^{\dagger}$, Yuqin Yang, Xuemei Huang, Nana Han, Xiaojing Liu, Xiaoyu Lin, Tao Ma, Bing Xu, Penglong Wang ${ }^{*}$ and Haimin Lei ${ }^{*}$

\begin{abstract}
Background: Oral administration of insulin (INS) could be absorbed into systemic circulation only if the carrier protected it from the hostile gastrointestinal conditions. However, traditional macromolecular carriers have not totally overcome challenges in addressing these biological barriers.

Result: In this study, inspired by small molecule natural products (SMNPs), we demonstrate the multi-functional selfassembly nanoparticles (BA-AI NPs) originating from baicalin (BA) and $\mathrm{AlCl}_{3}$ through coordination bonds and hydrogen bonds. As a novel carrier for oral insulin delivery (INS@BA-AI NPs), it displayed effective capacity in pH stimuliresponsive insulin release, intestinal mucoadhesion and transepithelial absorption enhance. Meanwhile, BA improved the paracellular permeability for insulin absorption, because of its downregulation at both mRNA and protein level on internal tight junction proteins. In vivo experiments exhibited remarkable bioavailability of INS and an ideal glucose homeostasis in the type I diabetic rat model.
\end{abstract}

Conclusion: This study offers a novel frontier of multi-functional carriers based on SMNPs with self-assembly character and bioactivity, which could be a promising strategy for diabetes therapy.

Keywords: Oral insulin, Small molecule natural product, Multi-functional nanoparticles, pH-sensitive, Mucoadhesive, Tight junction

*Correspondence: wpl581@126.com; hm_lei@126.com

${ }^{\dagger}$ Xiaohui Jia and Zhihua Yuan contributed equally to this work

School of Chinese Pharmacy, Beijing University of Chinese Medicine,

Beijing 102488, People's Republic of China

(c) The Author(s) 2022. Open Access This article is licensed under a Creative Commons Attribution 4.0 International License, which permits use, sharing, adaptation, distribution and reproduction in any medium or format, as long as you give appropriate credit to the original author(s) and the source, provide a link to the Creative Commons licence, and indicate if changes were made. The images or other third party material in this article are included in the article's Creative Commons licence, unless indicated otherwise in a credit line to the material. If material is not included in the article's Creative Commons licence and your intended use is not permitted by statutory regulation or exceeds the permitted use, you will need to obtain permission directly from the copyright holder. To view a copy of this licence, visit http://creativecommons.org/licenses/by/4.0/. The Creative Commons Public Domain Dedication waiver (http://creativeco mmons.org/publicdomain/zero/1.0/) applies to the data made available in this article, unless otherwise stated in a credit line to the data. 


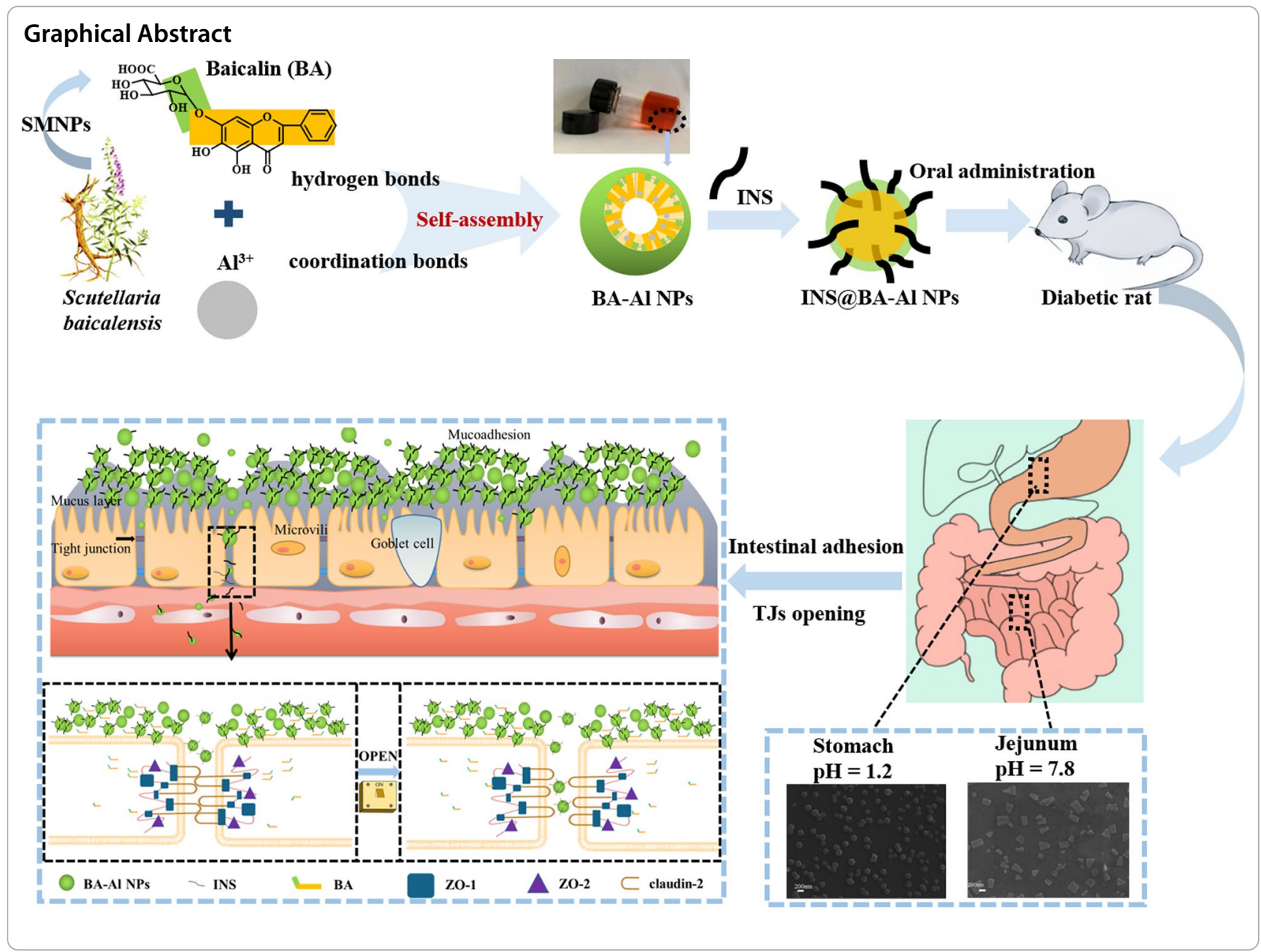

\section{Introduction}

Diabetes mellitus is a pervasive, insidious and lifelong metabolic disease that threatens the health of 466 million people in the world in 2021 according to a report from the World Health Organization and this number is anticipated to increase to 625 million by 2040 worldwide $[1,2]$. To date, subcutaneous parenteral still remain the conventional way to deliver insulin (INS) daily. However, subcutaneous injections of INS treatment for type 1 diabetes always causes patients pain and local tissue infection $[3,4]$. Orally administered INS, on the other hand, has received a lot of attention due to its patient friendly, non-invasive and convenient character [5-7]. Unfortunately, the bioavailability of oral INS is still limited (less than $2 \%$ ) by harsh biological barriers including gastric acid and intestinal mucosal $[8,9]$. The strategy to overcome these barriers is to use functional platforms, which protects INS from violent $\mathrm{pH}$ fluctuations in gastrointestinal tract, at the same time that improve the permeability via paracellular or transcellular transport and safety. $[10,11]$. The existing carriers produced by natural/ synthetic macromolecule (such as chitosan [12], hyaluronic acid [13], etc.) are used to meet the requirement $[14,15]$. However, these carriers need conjugate ligands such as cell-penetrating peptides [16], surfactants and zonula occludens toxin to open the tight junctions (TJs) in paracellular way [17], which may damage the intestinal epithelium[18]. In addition, they require synthesis or structural modification, which might cause toxicity and side effects during degradation and metabolism in the human body [19]. The deficiencies of carriers based on macromolecule might have hindered the clinical translation of oral INS. Therefore, it is urgent to search for a safe and multi-functional carrier for oral INS delivery.

Small molecule natural products (SMNPs) have been extensively investigated owing to their available pharmacological activity, good biocompatibility and long history of clinical usage [20,21]. With the continuous development of supramolecular self-assembly technology, their application as a part of biomedically functional delivery vehicles has been proposed to construct in drug delivery system without any structural modification or 
organic solvent $[22,23]$. The delivery carriers produced by specific SMNPs not only have satisfactory safety but also have stimuli-sensitive characteristics to control the release of agents [24]. More importantly, SMNPs confer significant bioactive activities, which can further play a synergistic role to treat disease without the help of any additives [25]. Therefore, compared with large molecular compounds, the carrier prepared by self-assembly technology of SMNPs have many significant advantages in oral INS transport. However, to our best knowledge, these carriers have not been exploited so far, which has greatly hindered the rapid development in self-assembled SMNPs and oral INS field.

Baicalin (BA, Fig. 1a), as a SMNPs, belonging to flavonoids family separated from Scutellaria baicalensis, has been broadly used for different applications in the research and clinic. Our previous study has found that BA has self-assembled character to form nanoparticles with enhancement effect and good biocompatibility [26]. Recently, it has been reported that BA could act as an effective absorption enhancer to modulate integrity of the TJs, which may benefit to the INS oral administration [27]. Despite all the advantages of the BA, there is no multi-functional carrier that can combine these advantages to achieve the application of oral INS.

In this work, $\mathrm{BA}$ and $\mathrm{AlCl}_{3}$ were used to prepare nanoparticles (BA-Al NPs) via facile and green self-assembly strategy without any organic solvent and complicated preparation process to delivery INS for oral administration (INS@BA-Al NPs). Combing with a series of spectral, mass spectrometry and thermodynamic methods, we found that BA-Al NPs were mainly driven by hydrogen bonds and metal-ligand coordination bonds. Serving as a protein delivery vehicle and drug permeability enhancer, BA-Al NPs could protect INS from being degraded under severe acidic conditions in stomach, elicit release under alkaline condition in intestine and extend retention time. In addition, BA-Al NPs disassembled and released BA to downregulate the TJs proteins expression and further improved the absorption of INS to maintain glucose homeostasis through modulating TJs. Meanwhile, in vivo experiments exhibited remarkable bioavailability $(8.88 \pm 1.05 \%)$ of INS and an ideal glucose homeostasis in the diabetes model. The combination of multi-functional biomaterial and significant therapeutic performance makes the naturally derived BA-Al
NPs nanocarrier a promising platform for drug delivery system.

\section{Materials and methods \\ Preparation of the BA-AI NPs and INS@BA-AI NPs}

BA-Al NPs were prepared via one-pot preparation procedures. Briefly, BA was dispersed in deionized water and adjusted to $\mathrm{pH}=7$ with sodium hydroxide $(\mathrm{NaOH})$ solution under vigorous stirring to obtain the BA solution. Afterward, $\mathrm{AlCl}_{3}$ was added into $\mathrm{BA}$ solution at $60{ }^{\circ} \mathrm{C}$ under a constant $\mathrm{BA} / \mathrm{AlCl}_{3}$ molar ratio of 2:1. After stirring for $2 \mathrm{~h}$, the mixture of $\mathrm{BA}$ and $\mathrm{AlCl}_{3}$ formed the self-assembled BA-Al NPs. For INS-loaded BA-Al NPs preparation, INS was firstly dissolved in hydrochloric acid solution $(\mathrm{pH}=2)$ before being added into BA-Al NPs. After stirring overnight, INS-loaded BA-Al NPs (INS@BA-Al NPs) was obtained and stored at $4{ }^{\circ} \mathrm{C}$ for future use. During the encapsulation of BA-Al NPs, maintaining the structural integrity of INS under different $\mathrm{pH}$ conditions is crucial to its therapeutic effect. Ultraviolet-visible circular dichroism (Far-UV CD) spectrophotometry and fluorescence spectra were used to monitor the secondary structure of INS under different $\mathrm{pH}$ conditions (Additional file 1: Fig. S1).

\section{Characterization of the BA-AI NPs}

The morphology of BA-Al NPs was imaged on scanning electron microscopy (SEM, ZEISS-SUPRA55, Germany) and transmission electron microscopy (TEM, JEM 2100F, JOEL, Tokyo, Japan). Dynamic light scattering (DLS) and zeta potential of the nanoparticles were carried out to collect the size distribution and charge properties using a Malvern Zetasizer NanoZS (DLS; Zetasizer Nano ZS 90, Malvern Instrument, UK). Loss modulus (G") and storage modulus (G') measurements were operated on a rotated rheometer (Physica MCR301, Aaton paar, Austria). To explore the effects of different temperatures on nanoparticles, the results were measured at $25{ }^{\circ} \mathrm{C}$ and $37{ }^{\circ} \mathrm{C}$. In parallelplate mode, the dynamic frequency scanning was performed at $0.5 \%$ strain, and the angular frequency was performed at $0.1-100 \mathrm{rds} \cdot \mathrm{s}^{-1}$. The scanning time was held for $1340 \mathrm{~s}$ at $25{ }^{\circ} \mathrm{C}$ and $661 \mathrm{~s}$ at $37^{\circ} \mathrm{C}$. An UV-vis spectrophotometer (HITACHI UH5300, Japan) with the scanning range from 200 to $600 \mathrm{~nm}$ was used to detect UV spectra of the BA-Al NPs and BA. The basic

(See figure on next page.)

Fig. 1 Chemical structure of BA (a); Macrograph of the hydrogel (b); FESEM image of the nanoparticles (c); TEM image of the nanoparticles (d); The hydrodynamic diameters of the nanoparticles $(\mathbf{e})$; The zeta potential of the nanoparticles $(\mathbf{f})$; The storage modulus $\left(\mathrm{G}^{\prime}\right)$ and loss modulus $\left(\mathrm{G}^{\prime \prime}\right)$ of the hydrogel as a function of angular frequency at $25^{\circ} \mathrm{C}$ and $37^{\circ} \mathrm{C}(\mathbf{g})$; The storage modulus $\left(\mathrm{G}^{\prime}\right)$ and loss modulus $\left(\mathrm{G}^{\prime \prime}\right)$ of hydrogel at $25^{\circ} \mathrm{C}$ and $37^{\circ} \mathrm{C}$ in $600 \mathrm{~s}$ (h) 
a<smiles>O=C(O)[C@H]1O[C]([I+])[C@@H](O)[C@@H](O)[C@@H]1O</smiles><smiles>C1CCCC1</smiles><smiles>COCC(=O)C=C(OC)c1ccccc1</smiles>

C

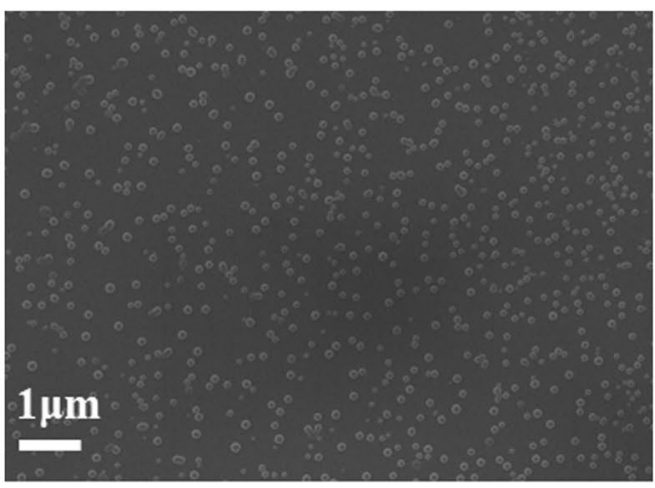

e
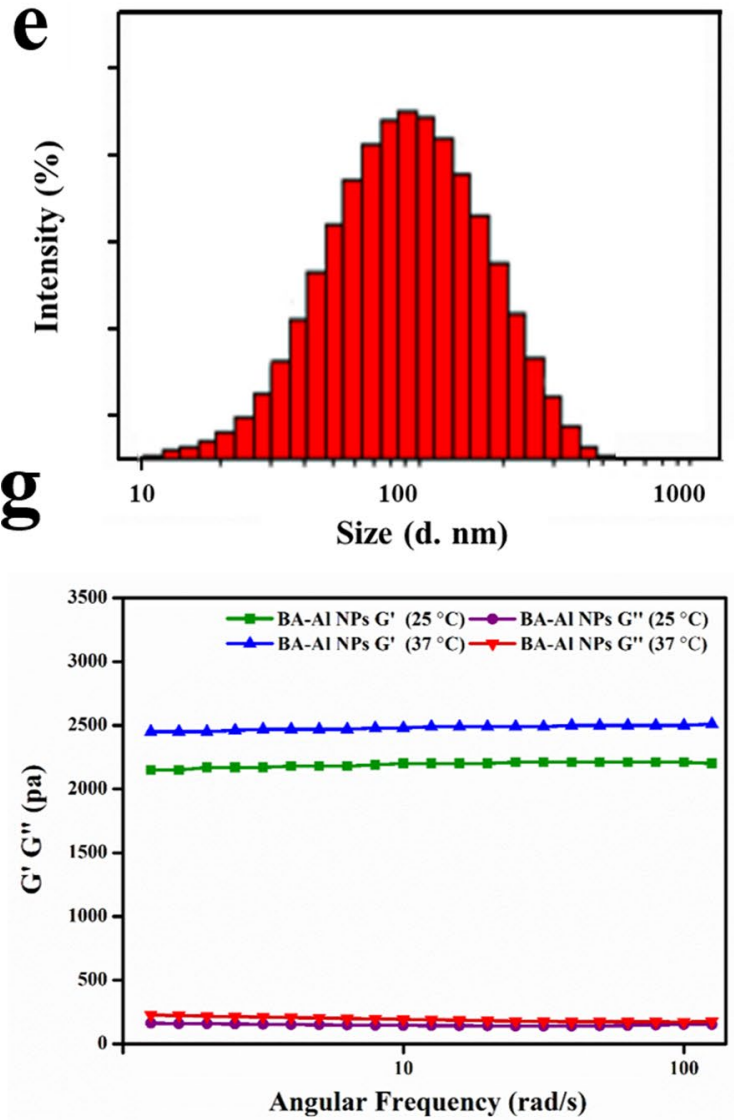

b

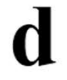

f
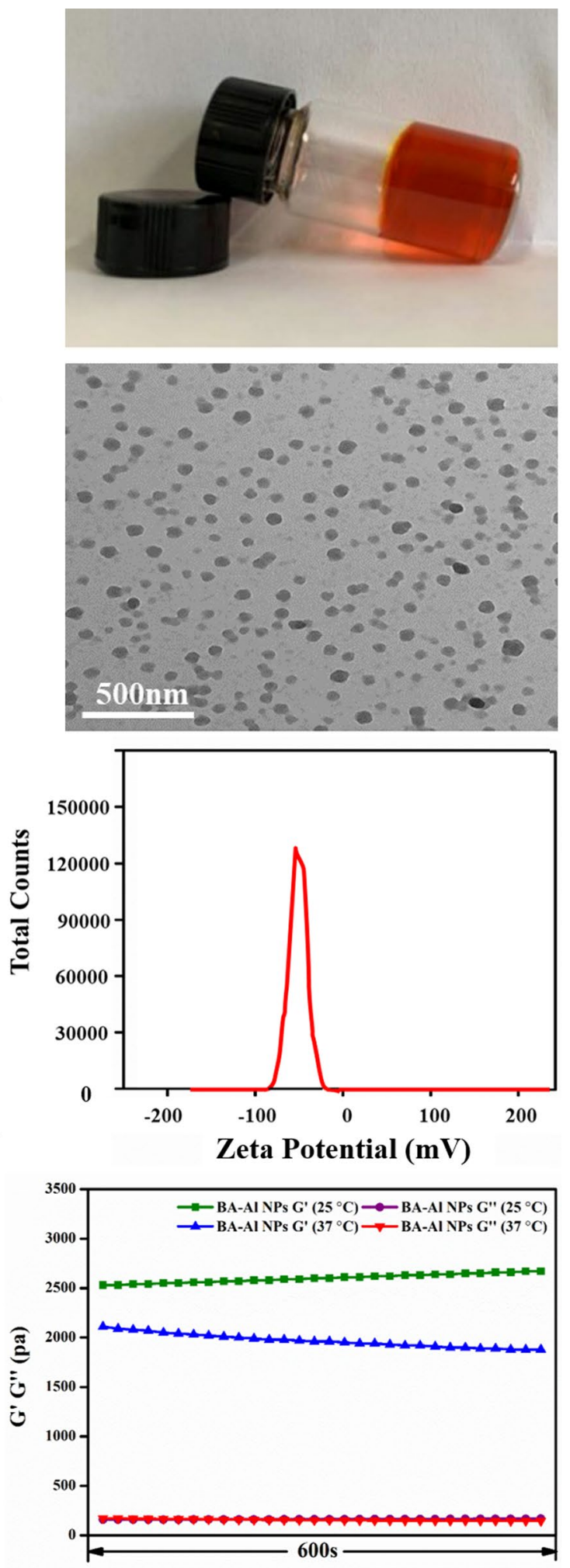

Fig. 1 (See legend on previous page.) 
unit of BA-Al NPs was analyzed by a high-resolution mass spectroscopy (static spray-HRMS, Waters, USA). CD spectra of BA and BA-Al NPs were measured using Chirascan V100 (Applied Photophysics, UK) for the range $200-600 \mathrm{~nm}$. The wavelength and bandwidth were set to $280 \mathrm{~nm}$ and $2 \mathrm{~nm}$, respectively. Fourier transform infrared (FT-IR) characterization of BA, and the self-assembled BA-Al NPs was recorded on a Fourier transform infrared spectrometer (Alpha II, Bruker, Germany) with a frequency range of $400-4000 \mathrm{~cm}^{-1}$. X-ray diffraction (XRD, D8A25, Bruker, Germany) was carried out on Ultima IV (Rigaku Japan) to identify structure of the BA-Al NPs. The 2-theta was measured at $5^{\circ}-50^{\circ}$ with $40 \mathrm{~kW}$ and $40 \mathrm{~mA}$, and the scanning speed was $3^{\circ} \mathrm{min}^{-1}$.

\section{In vitro release of insulin from INS@BA-AI NPs}

To evaluate the release of the INS@BA-Al NPs, it was dispersed in $5 \mathrm{~mL}$ simulated gastric fluid $(\mathrm{pH}=1.2)$ and simulated intestinal fluid ( $\mathrm{pH}=7.8$ ), respectively. Then it was incubated at $37^{\circ} \mathrm{C}$ with continuous shaking at $80 \mathrm{rpm}$ using a constant-temperature shaker (SHA-B, Guohua Co., Ltd., China). At specific time intervals, the sample was taken out, analyzed with enzyme linked immunosorbent assay (ELISA, SEKR-0033, Beijing Solarbio Science \& Technology Co., Ltd) and the micrographs were recorded.

\section{Cellular uptake analysis}

MDCK cells at logarithmic growth stage were digested by trypsin and inoculated on $35 \mathrm{~mm}$ laser confocal dishes with a density of $1 \times 10^{5}$ cells per well. After the cells were adherent to the wall for $24 \mathrm{~h}$, the supernatant was discarded, and the culture medium containing $10 \mu \mathrm{g} / \mathrm{mL}$ free-form Cy7 dye and $10 \mu \mathrm{g} / \mathrm{mL}$ Cy7@BA-Al NPs was added and incubated for $1 \mathrm{~h}$ and $4 \mathrm{~h}$ respectively. Then the upper culture medium was removed. The cells were gently washed with cold PBS $(\mathrm{pH}=7.4)$ for 3 times and fixed in a $4{ }^{\circ} \mathrm{C}$ refrigerator with $70 \%$ ethanol solution for $30 \mathrm{~min}$. Then the cells were stained with $10 \mu \mathrm{g} / \mathrm{mL}$ DiR and the fluorescence state of the cells was observed under a confocal laser scanning microscopy (CLSM).

\section{Animal}

Male Wistar rats $(250 \pm 5 \mathrm{~g})$ were provided by the Institutional Animal Care and Use Committee (IACUC) of Beijing University of Chinese Medicine (Beijing, China). The rats received a balanced diet and tap water ad libitum. All experiments were carried out in accordance with the guidelines for the Care and Use of Experiment Animals in IACUC. Diabetes was induced in Wistar rats by single intraperitoneal injection streptozotocin (STZ) in citrate buffer (dissolved in $10 \mathrm{mM}$ citrate buffer at $\mathrm{pH}=4.5$ at a dose of $75 \mathrm{mg} / \mathrm{kg}$ body weight for 3 days to get type I diabetic rats. Two weeks after the STZ treatment, rats were type I diabetic rats when their fasting blood glucose levels exceeded $300 \mathrm{mg} / \mathrm{dL}$.

\section{Biodistribution and mucoadhesion study of BA-AI NPs}

The mucoadhesion and biodistribution of BA-Al NPs were studied via small animal imaging system in vivo (Maestro 2, CRI, USA). Overnight-fasted mice were given two formulations (Free form Cy7, Cy7@BA-Al NPs) by intragastric administration with a Cy7 dosage of $2.5 \mathrm{mg} /$ $\mathrm{kg}$. After $0.5 \mathrm{~h}, 2 \mathrm{~h}, 4 \mathrm{~h}$ and $12 \mathrm{~h}$, they were anesthetized with $1.5 \%$ isoflurane in $100 \%$ oxygen. Fluorescence images of whole body of mice were obtained. And then, the animals were opened by a midline incision when they sacrificed. Major organs of mice's body were removed to observe Cy7 level, including intestine, heart, liver, spleen, lung, and kidneys at different times, and the total amount of fluorescence in the organs was measured by fluorescence spectrometer (IVIS, PerkinElmer, USA).

\section{Real-time (RT)-PCR analysis}

Total RNA was extracted from Caco-2 cells using TRIzol (Takara). In total, $1 \mu \mathrm{g}$ of the total RNA of each sample was reversely transcribed into cDNA using Prime- Script RT master mix (Takara) in a total volume of $10 \mu \mathrm{L}$. cDNA templates were then amplified with specific primers for target genes in the ABI ViiA 7 real-time PCR system (Applied Biosystems) using 2X SYBR Green PCR Master Mix (Applied Biosystems). Expression of gene of each sample was normalized to the endogenous control $\beta$-actin, and presented as $2^{-\Delta \Delta \mathrm{Ct}}$ using the comparative $\mathrm{Ct}$ method. Primer sequences for qPCR analyses are listed in Table 1.

\section{Western blotting}

Total protein was either extracted from Caco-2 cells using ice-cold RIPA buffer (25 mM Tris- $\mathrm{HCl}, 150 \mathrm{mM}$ $\mathrm{NaCl}, 1 \% \mathrm{NP}-40,1 \%$ sodium deoxycholate, 0.1\% SDS, complete protease cocktail (Roche)). Protein samples at $10 \mu \mathrm{g}$ were separated by $7.5-15 \%$ SDS-PAGE and electrophoretically transferred to polyvinylidene difluoride membranes (Bio-rad). After blocking with 5\% non-fat milk, membranes were incubated with primary antibodies overnight at $4{ }^{\circ} \mathrm{C}$. After rinsing, membranes were incubated with appropriate secondary antibody conjugated with HRP at room temperature for $1 \mathrm{~h}$. The positive immunoreactions were detected with $\mathrm{x}$-ray film (Fuji) by chemiluminescence using an ECL kit (GE Healthcare). The relative expression of proteins was quantified using 
Image J software (Wayne Rasband, NIH, USA). The antibodies are listed in Table 2 .

\section{Immunofluorescence analysis}

Caco- 2 cells were rinsed with prewarmed PBS and permeabilized with cold ethanol $\left(4^{\circ} \mathrm{C}\right)$ for $30 \mathrm{~min}$. Nonspecific binding sites were blocked with $1 \%$ BSA in PBS for 10 min. Cells were incubated in 1\% BSA in PBS with primary antibodies: anti-ZO- $1(20 \mu \mathrm{g} / \mathrm{ml})$ for $1 \mathrm{~h}$ at room temperature. Cells were washed three times with $1 \%$ BSA in PBS and incubated with FITC-conjugated goat-anti rabbit antibodies (1:50-100) as appropriate for $1 \mathrm{~h}$ at room temperature. Cells were washed three times with $1 \%$ BSA in PBS and analysis on a Confocal Laser Scanning Microscope (Leica TCS SP8).

\section{In vivo pharmacological activity of INS@BA-AI NPs}

Type I diabetic rats were fasted overnight and remained free access to water before testing. Model rats were given normal saline (NS) by intragastric administration. BA-Al NPs loaded with INS (INS@BA-Al INS 50 IU $/ \mathrm{kg}$ ) was administered orally to the diabetic animals. Free-form INS $(50 \mathrm{IU} / \mathrm{kg})$ was administered orally by intragastric administration as a negative control. Those subjected to subcutaneous (SC) injection of INS solution $(5.0 \mathrm{IU} / \mathrm{kg}$ ) were used as a positive control ( $\mathrm{n}=5$ for each test group). The blood samples were taken from tail vein and glucose level was checked using Bayer's glucose meter at regular time interval $(2 \mathrm{~h})$. Blood samples were collected from the tail vein of rats prior to drug administration and at different time intervals after dosing. The blood glucose levels then measured using a glucose meter (LifeScan Inc., Milpitas, CA, USA).
To evaluate the bioavailability of BA-Al NPs after peroral treatment, the plasma INS level was measured. The experimental method of blood collection is the same as before, and the serum was separated by centrifugation at $5000 \mathrm{rpm}$ for $10 \mathrm{~min}$ at $4{ }^{\circ} \mathrm{C}$, and stored at $-20{ }^{\circ} \mathrm{C}$. Serum INS concentrations were measured using enzyme-linked immunosorbent assay (ELISA, SEKR-0033, Beijing Solarbio Science \& Technology Co.,Ltd). The relative bioavailability (BAR) of test nanoparticles after peroral treatment was calculated using Eq. (1):

$$
\begin{aligned}
\operatorname{BAR}= & {\left[\operatorname{AUC}_{(\text {oral })} \times \operatorname{DOSE}_{(\mathrm{sc})}\right] / } \\
& {\left[\operatorname{AUC}_{(\mathrm{sc})} \times \operatorname{DOSE}_{(\text {oral })}\right] \times 100 \% }
\end{aligned}
$$

where AUC is the total area under the plasma INS concentration versus time curve.

All animals received a balanced diet and tap water ad libitum. Animals were carefully observed for the onset of any signs of toxicity and changes in body weight.

\section{The protective effect of BA-AI NPs on tissue damage}

Before the text, diabetic rats were fasted overnight and remained free access to water. NS was administered orally to elucidate the normal shape of the tissue as negative control. Free form INS (50 IU/kg) and INS@ BA-Al NPs $(50 \mathrm{IU} / \mathrm{kg})$ were administered orally by intragastric administration, respectively. The SC injection of INS solution $(5.0 \mathrm{IU} / \mathrm{kg})$ were used as a positive control. The harvested organs (heart, liver, spleen, lung, and kidneys) were fixed in $10 \%$ paraformaldehyde after necropsy, and

Table 1 List of primers used in the study

\begin{tabular}{lll}
\hline Target & Sense $\mathbf{( 5}^{\prime} \mathbf{-} \mathbf{3}^{\prime} \mathbf{)}$ & Antisense $\mathbf{( 5}^{\prime} \mathbf{-} \mathbf{3}^{\prime} \mathbf{)}$ \\
\hline ZO-1 & CAAGATAGTTTGGCAGCAAGAGATG & ATCAGGGACATTCAATAGCGTAGC \\
ZO-2 & CGGATTCCAGACAAGGT & CCTTCAGAGACCCAGA \\
Claudin-1 & CCAACGCGGGGCTGCAGCT & TTGTTTTTCGGGGACAGGA \\
-actin & AACTACCTTCAACTCCATCA & GAGCAATGATCTTGATCTTCA \\
\hline
\end{tabular}

Table 2 List of antibodies used in the study

\begin{tabular}{lllll}
\hline Antigen & WB dilutions & Source/Host & Company & Catalog number \\
\hline ZO-1 & $1: 1000$ & Rabbit & Cell Signaling Technology & $\# 13663$ \\
ZO-2 & $1: 1000$ & Rabbit & Cell Signaling Technology & $\# 2847$ \\
Claudin-1 & $1: 1000$ & Rabbit & Cell Signaling Technology & $\# 13995$ \\
B-actin & $1: 1000$ & Rabbit & Cell Signaling Technology & $\# 4970$ \\
Rabbit lgG secondary & $1: 2000$ & Goat anti-rabbit lgG-HRP & Cell Signaling Technology & $\# 7074$ \\
antibody & & & & \\
\hline
\end{tabular}


then washed, dehydrated, waxed, embedded, sectioned and sealed. The morphological characteristics of organs was performed by hematoxylin and eosin stain (H\&E) and observed under microscope.

\section{Statistical analysis}

All data are presented as mean \pm standard deviation (SD). Pairs of groups was analyzed by the one-tailed Student's test. A statistical difference was considered when significance $p$ value was less than 0.05 .

\section{Results and discussion}

\section{Morphological and gelation characteristics of BA-AI NPs}

We have been working on BA for a long time, and its selfassembly behavior has been previously reported [23]. In this work, we prepared BA-Al NPs by only one step without complex process. After mixing of $\mathrm{BA}$ and $\mathrm{AlCl}_{3}$ in an aqueous solution, the transparent orange-red hydrogel was obtained by heating in water bath (Fig. 1b and Additional file 1: Fig. S2).

The field-emission scanning electron microscopy (FESEM) and transmission electron microscopy (TEM) were employed to observe micromorphology of the nanoparticles. As shown in Fig. 1c and d, the obtained nanoparticles were uniform sphere with mean diameter of roughly $100 \mathrm{~nm}$, and this result was consistent with that of dynamic light scattering $(\mathrm{PDI}=0.28 \pm 0.01$ ) (Fig. 1e). The diameter of nanoparticles could be beneficial to transport through TJs [4]. Furthermore, zeta potential of BA-Al NPs dissolved in aqueous solution was $-47.93 \pm 4.71 \mathrm{mV}$ (Fig. 1f), indicating stability of nanoparticles which were less likely to aggregate and precipitate [28].

To further determine mechanical properties of the hydrogel, rheological analysis was experimented by testing the storage modulus $\left(G^{\prime}\right)$ and loss modulus $\left(G^{\prime \prime}\right)$. Figure $1 \mathrm{~g}$ indicated that $\mathrm{G}^{\prime}$ was consistently higher than $\mathrm{G}^{\prime \prime}$ whether at $25^{\circ} \mathrm{C}$ or $37{ }^{\circ} \mathrm{C}$, which revealed that temperature had little effect on the nanoparticles and possessed great performance in biomedical fields. In Fig. 1h, dynamic time sweep data showed that $G^{\prime}$ was greater than $G^{\prime \prime}$ during the whole experiment of $600 \mathrm{~s}$, and crossover point was not noticed when doing the sweep experiments. The rheology analysis displayed the stability and homogeneous of the fabricated hydrogel [29].

\section{Self-assembly mechanism of BA-AI NPs.}

To thoroughly elucidate the structural properties of the BA-Al NPs, series of spectroscopy studies were implemented [30]. The Ultraviolet-visible (UV - vis) spectra of BA exhibited two significant absorption peaks at $275 \mathrm{~nm}$ (band II) and $312 \mathrm{~nm}$ (band I) (Fig. 2a). Compared with BA, there was an obvious bathochromic shift with band
II on the characteristic absorption peak of BA-Al NPs (from 275 to $285 \mathrm{~nm}$ ), but no change with band I was observed. The result indicated that 5-hydroxyl and 4-carbonyl group in A-ring of $\mathrm{BA}$ coordinated with $\mathrm{Al}^{3+}$ to form stable complex.

To obtain more intuitive complex fragment structure, high resolution mass spectrometry (HRMS) was performed. As shown in Fig. 2b, fragmentations of monomer $\left(m / z 447.0942[\mathrm{M}+\mathrm{H}]^{+}\right)$and dimer $(m / z 918.1439[2 \mathrm{M}$ $-2 \mathrm{H}+\mathrm{Al}+\mathrm{H}]^{+}$) were found in ESI positive ion mode, which represented $\mathrm{BA}$ and $\mathrm{BA}-\mathrm{Al}^{3+}$ complex respectively. The result showed that $\mathrm{Al}^{3+}$ attached to 4-carbonyl and 5-hydroxyl group of two BA and formed dimer through coordination bonds, which was consistent with the results of the UV-vis study. Meanwhile, the result of circular dichroism (CD) spectra (Fig. 2c) suggested that $\mathrm{Al}^{3+}$ transformed molecules from achiral to chiral component and induced the reinforcement of chiral features, which further indicated the formation of coordination bonds between $\mathrm{Al}^{3+}$ and $\mathrm{BA}$ [31].

Then Fourier transform infrared (FT-IR) spectra was determined to obtain more information on the nanoparticles. As shown in Fig. 2d, the spectra of unmodified BA displayed stretching vibration of the carbonyl group on glucuronic acid in $1725 \mathrm{~cm}^{-1}$, typical $\mathrm{C}_{4}=\mathrm{O}$ groups in $1658 \mathrm{~cm}^{-1}$ and $\mathrm{C}_{5}-\mathrm{O}$ groups in $1036 \mathrm{~cm}^{-1}$, respectively [32]. After forming nanoparticles, the main alterations in spectral absorption were as follows: down-field shift of $\mathrm{C}_{4}=\mathrm{O}$ groups (from $1658 \mathrm{~cm}^{-1}$ to $1632 \mathrm{~cm}^{-1}$ ) and $\mathrm{C}_{5}-\mathrm{O}$ groups (from 1036 to $1002 \mathrm{~cm}^{-1}$ ) implied $\mathrm{C}_{4}=\mathrm{O}$ and $\mathrm{C}_{5}$-O binding sites might be occupied by $\mathrm{Al}^{3+}$. The peak of carbonyl group on glucuronic acid in the BA-Al NPs was disappeared, reflecting that there might be hydrogen bonding interaction.

Next, we applied X-ray diffraction (XRD) to further prove formation of coordination bonds and hydrogen bonds of the directly self-assembled nanoparticles in wide-angle patterns (Fig. 2e) [33]. Compared with BA, the diffractogram of BA-Al NPs showed two strong sharp reflections at $2 \theta=31.745^{\circ}(\mathrm{d}=2.8164 \AA)$ and $2 \theta=45.456^{\circ}$ $(\mathrm{d}=1.9937 \AA)$. The sharp diffraction peaks were attributed to the partially ordered structure of the BA-Al NPs. The peak $(\mathrm{d}=2.8164 \AA)$ was due to the strong intermolecular hydrogen bond $\left(\mathrm{COOH}^{-}\right)$and the other peak $(\mathrm{d}=1.9937 \AA)$ was caused by the coordination bond

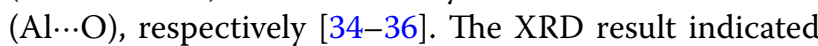
that incorporation of $\mathrm{Al}^{3+}$ rearranged the molecules to form coordination bonds and hydrogen bonds [37].

Isothermal titration calorimetry (ITC) was applied to detect the thermodynamic mechanism of the interaction between $\mathrm{BA}$ and $\mathrm{AlCl}_{3}$. As shown in Fig. $2 \mathrm{f}, \mathrm{AlCl}_{3}$ solution $(8 \mathrm{mM})$ was titrated into deionized water as benchmark to eliminate the interference of dilution heat, and 

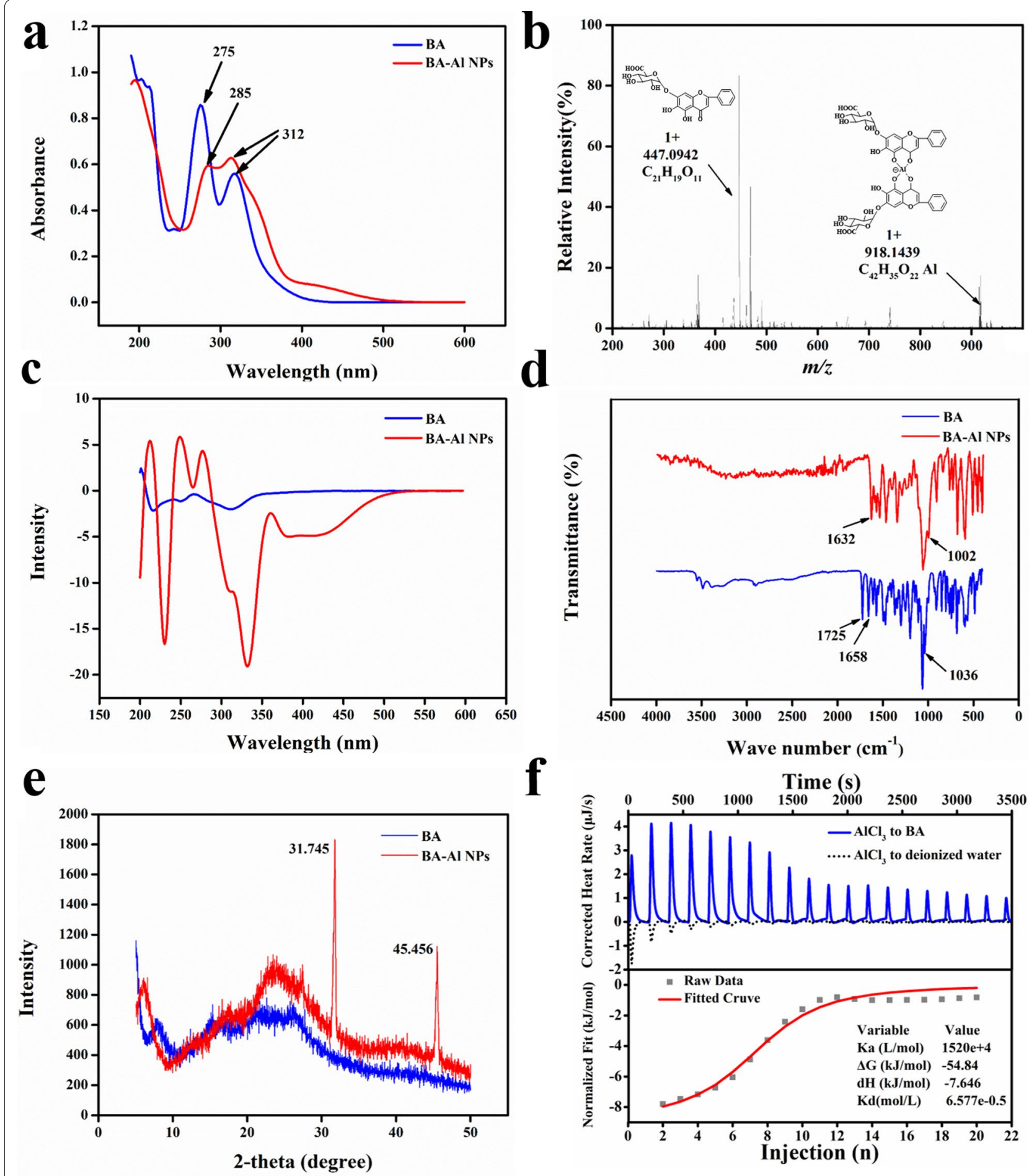

Fig. 2 UV-vis spectrum of BA and BA-AI NPS (a); ESI-HRMS spectrum of BA and BA-AI NPs (b); CD spectra of BA and BA-AI NPS (c) ; FT-IR spectra of BA and BA-Al NPs (d); XRD pattern of BA and BA-AI NPs (e); ITC raw data and fitted curve of BA solution titrated by $\mathrm{AlCl}_{3}$ solution (f)

$\mathrm{AlCl}_{3}$ solution $(8 \mathrm{mM})$ titrated $\mathrm{BA}$ solution $(1 \mathrm{mM})$ was set as an experimental group. The energy change data tested from ITC were summarized in Additional file 1:
Tables S1 and S2. The titration of $\mathrm{AlCl}_{3}$ solution into deionized water showed a downward titration profile, indicating an endothermic dilution process. However, 


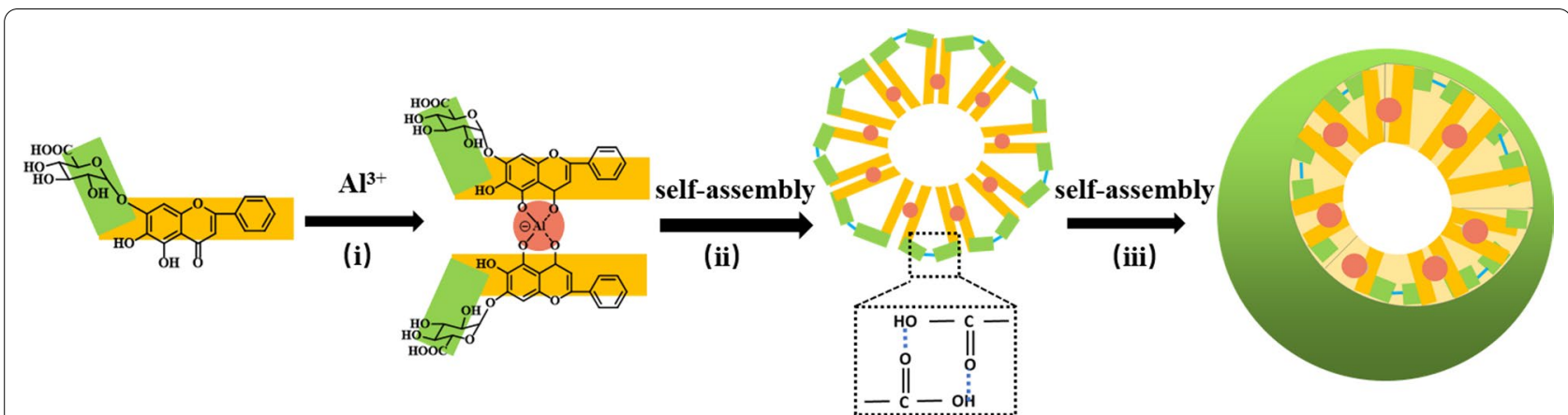

Scheme 1 A hypothetical mechanism of self-assembly formation of the spherical BA-Al NPs. (i) The carbonyl and hydroxy groups on the two BA self-assembled to form dimer by binding $\mathrm{Al}^{3+}$. (ii) The dimers are connected by intermolecular hydrogen bonds. (iii) The dimers cross-linked to form three-dimensional spherical nanoparticles

the titration of $\mathrm{AlCl}_{3}$ into $\mathrm{BA}$ revealed an utterly opposite trend and released much heat. The fitted S-shape curve generally presented strong interaction. Therefore, we confirmed that there was a strong interaction between $\mathrm{BA}$ and $\mathrm{AlCl}_{3}$. We also obtained binding thermodynamic parameters between them, and the negative value of $\Delta G\left(-54.84 \mathrm{~kJ} \cdot \mathrm{mol}^{-1}\right)$ indicated their binding reaction was spontaneous. $\Delta H\left(-7.646 \mathrm{~kJ} \cdot \mathrm{mol}^{-1}\right)$ and $T \Delta S\left(-16.617 \mathrm{~kJ} \cdot \mathrm{mol}^{-1}\right)$ indicated their binding was enthalpy-driven reaction, which meant the existence of hydrogen bonds [38]. All of the binding thermodynamic parameters illustrated a chemical reaction rather than physical combination in the well-organized self-assembly process [23].

In summary, all of UV-vis, HRMS, CD and FT-IR could infer that two BA connected with $\mathrm{Al}^{3+}$ to form dimer through coordination bonds. Both FT-IR and XRD further suggested not only coordination bonds, but hydrogen bonds were formed in the process of self-assembly. Furthermore, ITC demonstrated spontaneous reactions in the binding process were a chemical rather than physical reaction. Based on the above experimental results, as shown in Scheme 1, two BA molecules self-assembled to form a one-dimensional dimer through coordinate bond with $\mathrm{Al}^{3+}$. Dimers then were connected to form threedimensional spherical nanoparticles through intermolecular hydrogen bonds.

\section{In vitro release of INS from INS@BA-AI NPs}

To further explore the drug transport capacity of the prepared carrier, in vitro release behavior of $\mathrm{BA}-\mathrm{Al}$ NPs was studied under artificial gastric juice $(\mathrm{pH}=1.2)$ and artificial intestinal juice $(\mathrm{pH}=7.8)$ at $37{ }^{\circ} \mathrm{C}$, respectively. As displayed in Fig. 3A, the morphological of the INS@BA-Al NPs was integrated under acidic condition (Fig. 3a1), while under alkaline condition, INS@BA-Al NPs began to dissolve (Fig. 3a2). The main reason may be that two BA molecules were tightly bound by hydrogen bonds in an acidic environments. In contrast, INS@ BA-Al NPs became loose as destruction of intermolecular hydrogen bonds in an alkaline environment. Therefore, the BA-Al NPs has potential in drug delivery system due to its integrity can be controlled by changing $\mathrm{pH}$ circumstances.

We then evaluated controlled releasing function of INS@BA-Al NPs under different pH values. In Fig. 3b, the cumulative solubilization curves showed that the drug release rate was $12.4 \%$ of encapsulation INS by BA-Al NPs under the artificial gastric juice $(\mathrm{pH}=1.2)$, whereas $83.7 \%$ INS was released from BA-Al NPs under the intestinal gastric juice $(\mathrm{pH}=7.8)$. This demonstrated that the BA-Al NPs was $\mathrm{pH}$-sensitive and could control the release of INS under different $\mathrm{pH}$ conditions. Considering dramatic $\mathrm{pH}$ fluctuations in the gastrointestinal tract, this $\mathrm{pH}$-responsive property of BA-Al NPs is beneficial for retaining the stability of INS in stomach acid and controlling release of INS in the intestines.

\section{Cellular uptake analysis}

Confocal laser scanning microscopy (CLSM) was performed to detect MDCK cells incubated with BA-Al NPs to gain further insight into cellular adhesion and uptake of the nanoparticles [39]. As Fig. 3d and 3e showed, the intense green fluorescence Sulfo-Cyanine7 (Cy7) confirmed that BA-Al NPs was sufficiently stuck to MDCK cells and cytomembrane was labelled by red DiR iodide (DiR), and the yellow signal was overlap of Cy7 and DiR fluorescence. There was more significant yellow signal intensity in the cytomembrane of MDCK cells after $1 \mathrm{~h}$ incubated with Cy7@BA-Al NPs than free-form Cy7. As the incubation time extending to $4 \mathrm{~h}$, more Cy7@ BA-Al NPs adhered to cells, resulting in an increase in fluorescence intensity. We further used flow cytometry to research cellular uptake efficient of MDCK cells treated 
with Cy7@BA-Al NPs and free-form Cy7, Fig. 3c indicating that Cy7@BA-Al NPs possessed higher internalization ability in $1 \mathrm{~h}$ and $4 \mathrm{~h}$. Collectively, this phenomenon manifested that BA-Al NPs as oral delivery vehicle could be adhered around and taken into cells.

\section{Biodistribution and mucoadhesion of BA-AI NPs}

Besides drastic changes in $\mathrm{pH}$, the rapid removal at intestine is an important biological obstacle [40]. To investigate the effect of mucoadhesion of free-from $\mathrm{Cy} 7$ and Cy7@BA-Al NPs, they were orally administered to mice, and the fluorescent signal was observed by a small animal imaging system in vivo. From the whole body's fluorescence signal (Fig. 4a), mice administered with Cy7@ BA-Al NPs displayed more sustained fluorescence signal than free-form Cy7. As shown in Fig. 4b, with the time extended to 12 h, the Cy7@BA-Al NPs group still had continuous fluorescence in intestine, while $\mathrm{Cy} 7$ group had almost no fluorescence. The time-dependent change of fluorescence intensity was shown in Fig. 4c, the fluorescence signal stayed longer time at intestine of mice treated with Cy7@BA-Al NPs compared to free-form Cy7. The result suggested that mucoadhesive hydrogel could prolong the retention time of agent in intestine. In addition, as showed in Fig. $4 \mathrm{~d}$, organs were retrieved for ex-vivo imaging. The Cy7@BA-Al NPs fluorescence intensity at liver and kidney were higher than free $\mathrm{Cy} 7$ evidently, indicating systemic absorption and metabolism of Cy7@BA-Al NPs [41].

\section{Mechanism of BA-AI NPs actions}

Tight junctions (TJs) are the major obstacle to INS absorption in paracellular pathway. The integrity of TJs is crucial in expounding the mechanism of BA-Al NPsinduced TJs opening [42]. The protein-protein interaction between claudins (claudin-1) and $\mathrm{ZO}$ scaffolding proteins ( $\mathrm{ZO}-1, \mathrm{ZO}-2)$ is the major basis of integrity of TJs [43-45]. In this study, the mRNA and protein expression level of TJs proteins was tested by real-time (RT)-PCR and western blot (WB) analysis, respectively. The expression of TJs protein of Caco-2 cells after the administration of BA and BA-Al NPs was researched at both gene and protein level. The result demonstrated $\mathrm{BA}$ and BA-Al NPs could down-regulate or redistribute TJs proteins (Fig. 5a-c). In addition, as shown in Fig. 5d, the result of immunofluorescence staining also showed that expression of ZO-1 proteins of BA and BA-Al NPs treated $\mathrm{Caco}-2$ cells was significantly weakened and discontinuous, especially with respect to controls.

We hypothesized that BA-Al NPs could cause the TJs proteins to be downregulated, which might be attributed to the important role played by BA. Under the assumption, we further used molecular docking to study the potential interaction between $\mathrm{BA}$ and protein domain. The result showed that BA bound to $2 \mathrm{~h} 3 \mathrm{~m}$ of $\mathrm{ZO}-1$ simply and stably ( $\triangle G$ bind $=-7.7$ ), which might be what causes the nanoparticles to downregulate the TJs proteins. The hydrogen bond and pi-alkyl are mainly interaction between $\mathrm{BA}$ and the residues of $2 \mathrm{~h} 3 \mathrm{~m}$ (Fig. $5 \mathrm{e}$ ). In addition, the expression of claudin-1, ZO- 1 and $\mathrm{ZO}-2$ decreased after the administration of BA compared with the control group at both gene and protein level (Fig. 5ac). The result was consistent with previous report demonstrating that BA down-regulated or redistributed TJs proteins to influence the integrity of TJs $[17,27]$.

These findings suggested that expression of TJs-related genes and proteins of Caco- 2 cells induced by BA-Al NPs were related to the down-regulation and redistribution of TJs protein by BA. Interestingly, under the action of self-assembly, the bioavailability of BA in BA-Al NPs was increased, which may cause the down-regulation of most genes and proteins was more obvious by BA-Al NPs. BA-Al NPs could modulate epithelial barrier in human intestinal Caco-2 cells and has a potential to become an idea drug absorption enhancer through paracellular pathway (Fig. 5f).

\section{In vivo pharmacokinetics and pharmacodynamics of INS@ BA-Al NPs.}

To test our hypothesis and decipher regulation of blood glucose level of INS@BA-Al NPs after oral administration, in vivo hypoglycemic effect was investigated on type I diabetic rats. The blood glucose level-time profiles following administration of various INS formulations to diabetic rats were shown in Fig. 6a. As expected, no hypoglycemic effect was observed after diabetic rats orally administrated free-form INS, implying a poor hypoglycemic effect of insulin without an appropriate carrier. Subcutaneous (SC) injection of the insulin markedly reduced the blood glucose level in $0-2 \mathrm{~h}$, and subsequently its blood glucose level returned to initial level. INS@BA-Al NPs showed a remarkable reduction in blood glucose level and prolonged hypoglycemic time. This result suggested oral administration of INS@BA-Al NPs could steadily control the blood glucose and displayed an apparent reduction in blood glucose level.

The corresponding plasma INS concentration at different time were researched to evaluate relative bioavailability of INS [46]. As shown in Fig. 6b, in the group orally administered with the free-form INS, the amount of plasma INS was hard to detect. The group subcutaneously treated with free-form INS showed a maximum serum INS concentration at $1 \mathrm{~h}$ post-administration. The INS@ BA-Al NPs revealed a maximum concentration of plasma INS at $3 \mathrm{~h}$ post-administration which meant prolonged circulation time. The area under the concentration-time 


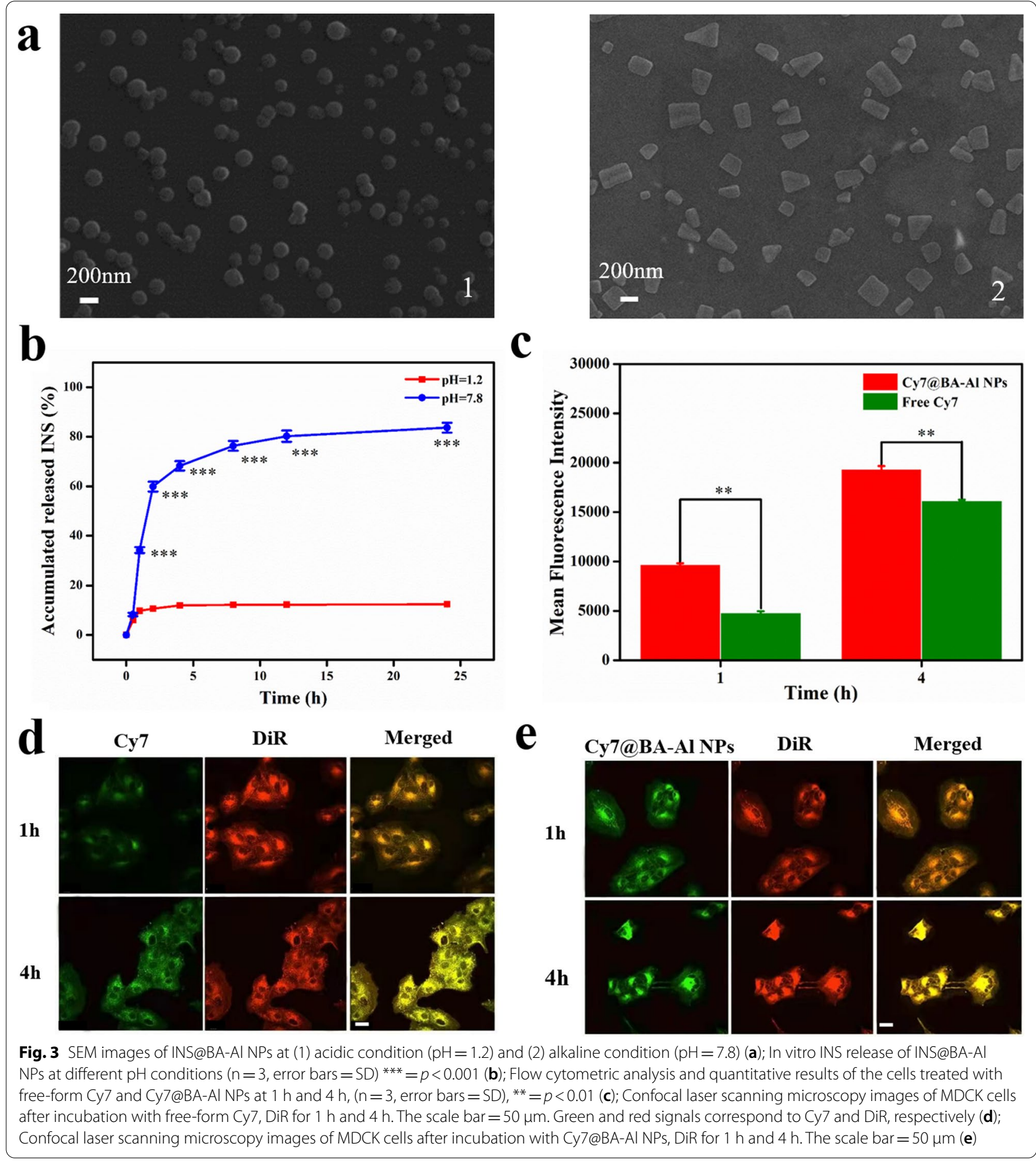

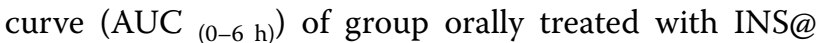
BA-Al NPs was $75.93 \pm 5.34 \mu \mathrm{IU} \cdot \mathrm{h} \cdot \mathrm{mL}^{-1}$, which corresponded to the relative bioavailability of INS found to be $8.88 \pm 1.05 \%$. These results demonstrated that the BA-Al NPs enhanced bioavailability of INS.
Simultaneously, we monitored body weight of rats to exam the therapeutic efficacy and potentially adverse effect of BA-Al NPs. As shown in Fig. 6c and Additional file 1: Table S3, distinct body weight changes were revealed in four different groups. The diabetic rats in normal saline (NS) and free-form INS group displayed 


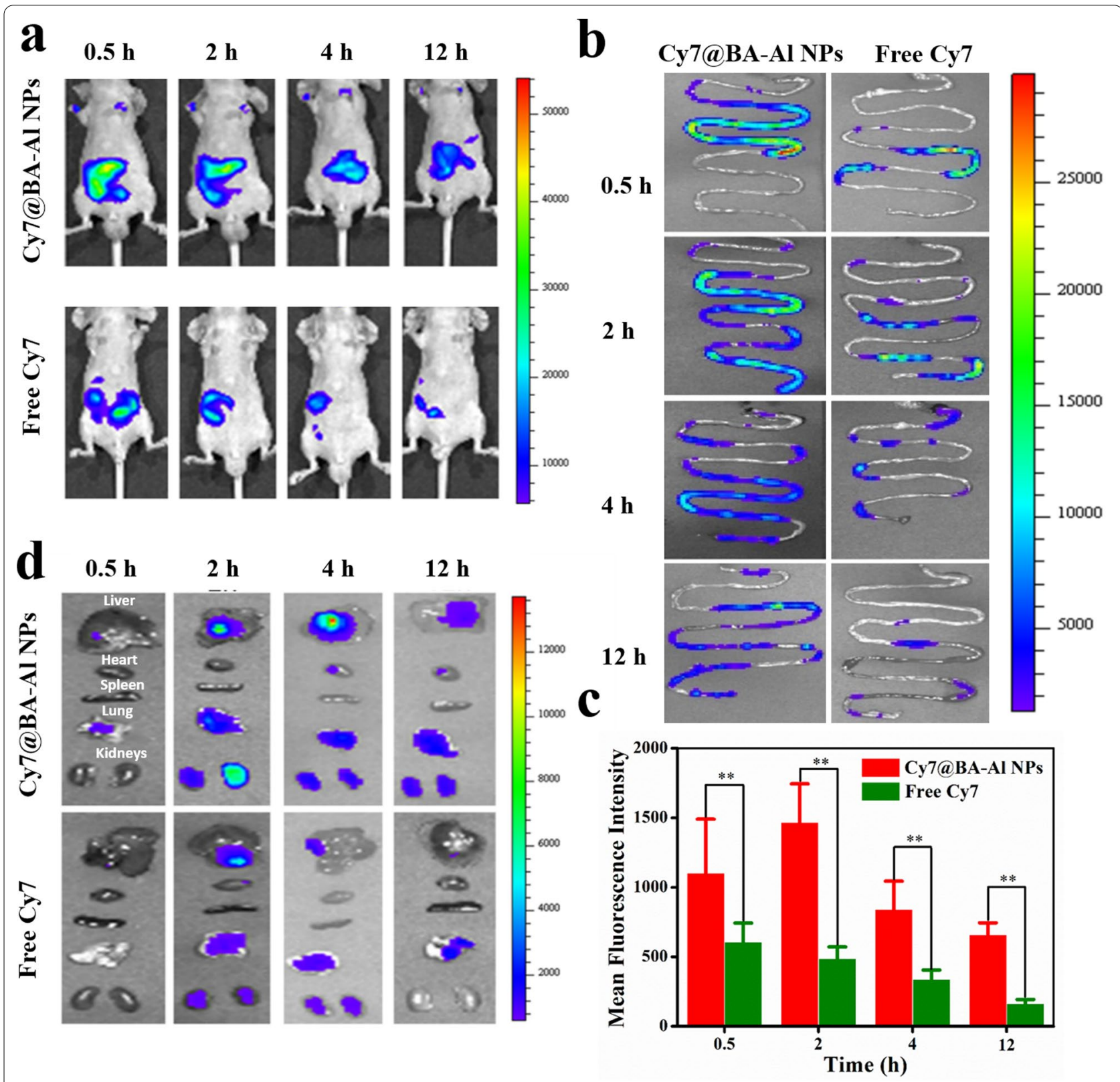

Fig. 4 Whole-body fluorescence images of mice at different time points after being treated with free-form Cy7 and Cy7@BA-Al NPs via oral administration (a); Fluorescence images of in vitro intestine at different time points after mice being treated with free-form Cy7 and Cy7@BA-Al NPs via oral administration (b); Flow cytometric analysis and quantitative results of in vitro intestine at different time points after mice being treated with free-form Cy7 and Cy7@BA-AI NPs via oral administration, $(n=3$, error bars $=\mathrm{SD}) .{ }^{* *}=p<0.01$ (c); Fluorescence images of organs at different time points after mice being treated with free-form Cy7 and Cy7@BA-Al NPs via oral administration (d)

(See figure on next page.)

Fig. 5 Gene expression levels of Claudin-1, ZO-1 and ZO-2 mRNAs in BA and BA-Al NPs-treated Caco-2 cells. Caco-2 cells treated with DMEM medium were used as a blank control ${ }^{*}=p<0.05,{ }^{* *}=p<0.01,{ }^{* * *}=p<0.001$ (a); Representative western blot of Claudin-1, ZO-1 and ZO-2 proteins in BA and BA-AI NPs- treated Caco-2 cells (b); Quantification of Claudin-1, ZO-1 and ZO-2 proteins using Image J. ${ }^{*}=p<0.05,{ }^{* *}=p<0.01$, ${ }^{* * *}=p<0.001$ (c); Immunofluorescence staining of TJ protein ZO-1 in BA and BA-AI NPs-treated Caco-2 cells (d); Molecular docking analysis of interaction between BA and 2h3m (crystal structure of ZO-1 PDZ1) (e); Schematic illustration showing the mechanism and consequence of BA-Al NPs mediated TJs modulating between intestinal epithelial cells (f) 

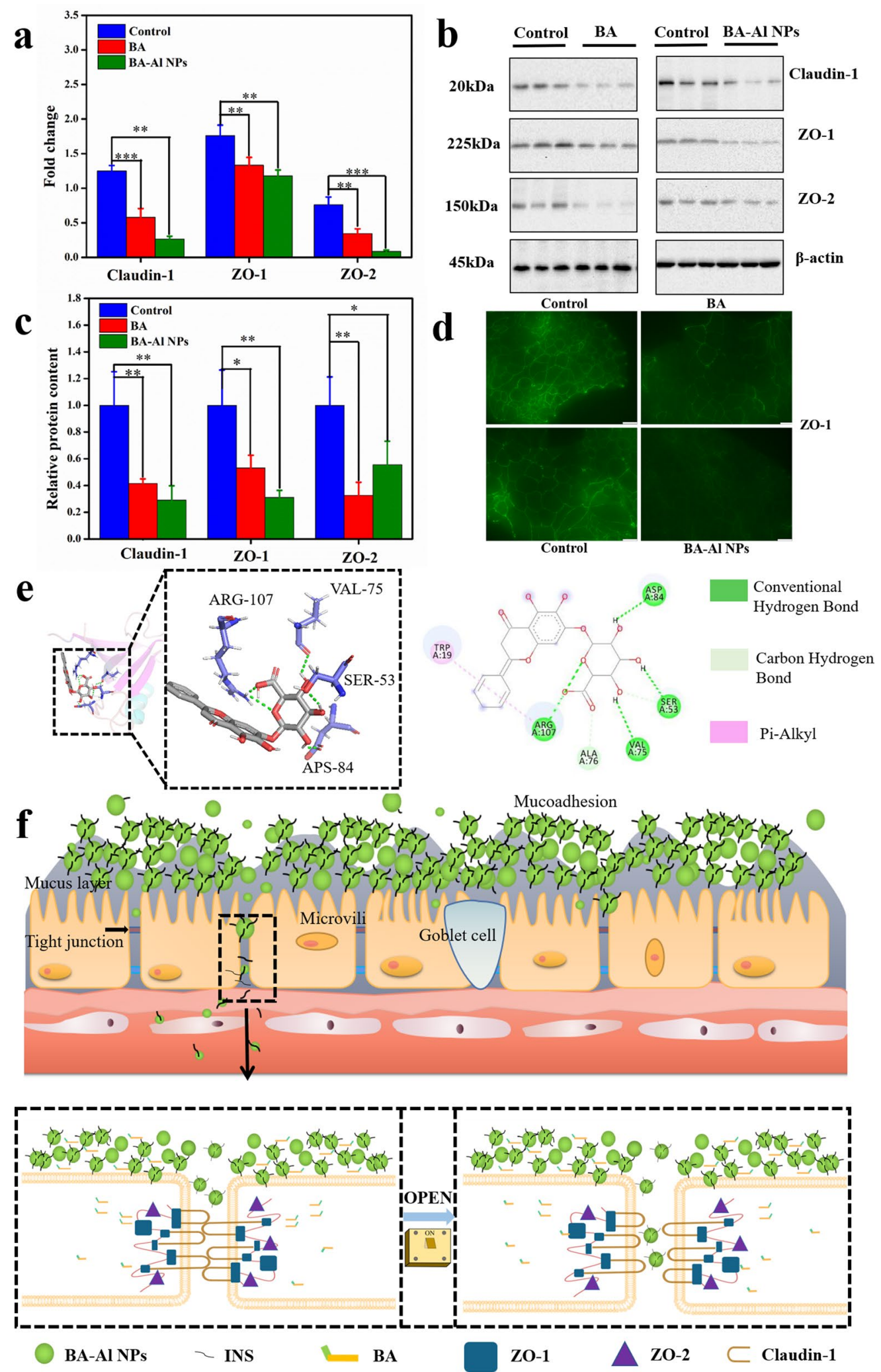

Fig. 5 (See legend on previous page.) 


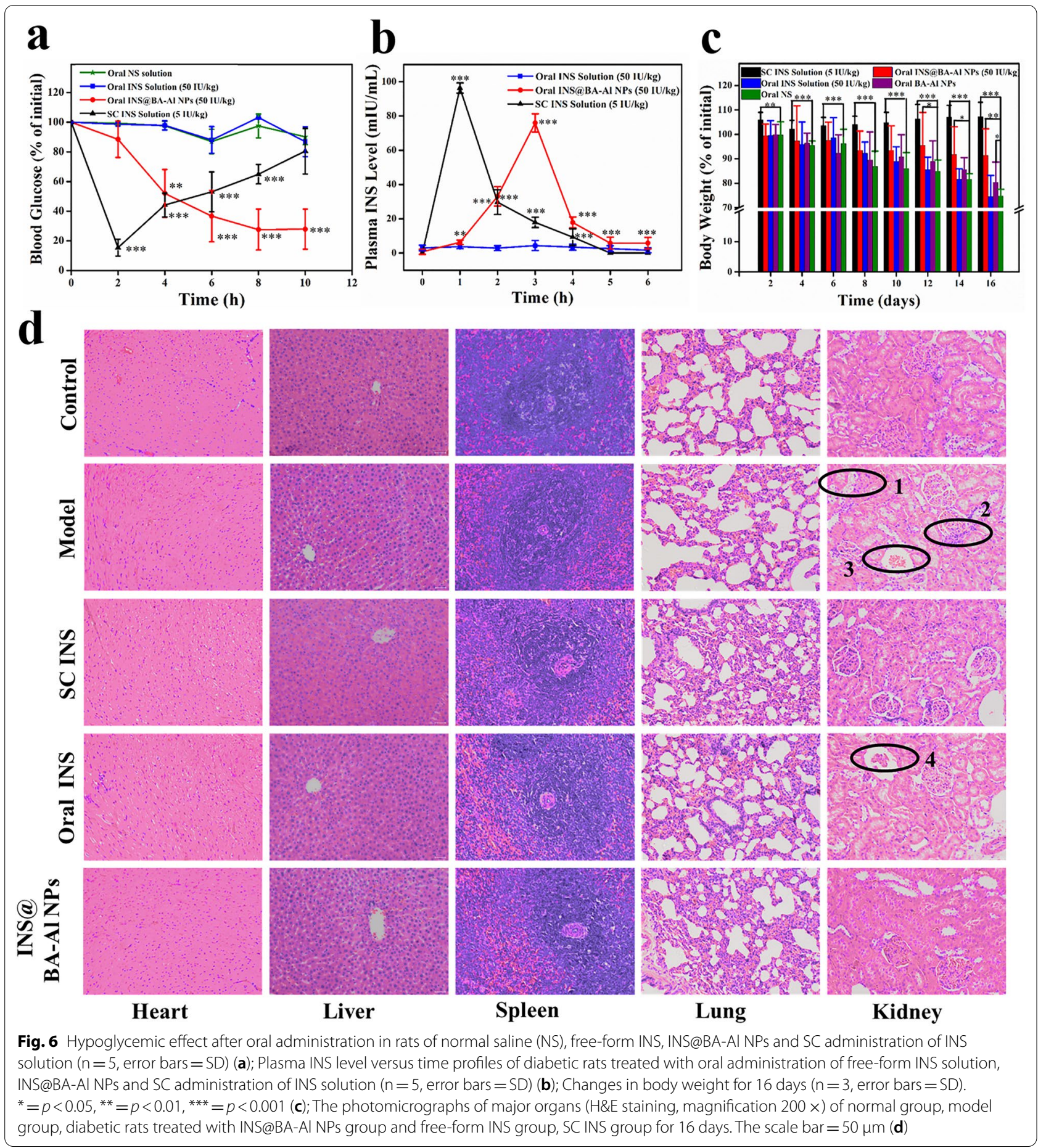

a sharp decrease in body weight, which revealed serious side effects induced by diabetic. While the INS@BA-Al NPs and BA-Al NPs treated groups unveiled a minor decline of body weight loss, showing therapeutical effect and reduced system toxicity.
The histologic sections stained with hematoxylin and eosin (H\&E) were carried out to estimate pharmacodynamic and long-term toxicity of INS@BA-Al NPs. As shown in Fig. 6d1, d2 and d3, the kidney in the model group showed edema of renal tubular epithelial cells, infiltration of inflammatory cells in renal interstitium, 

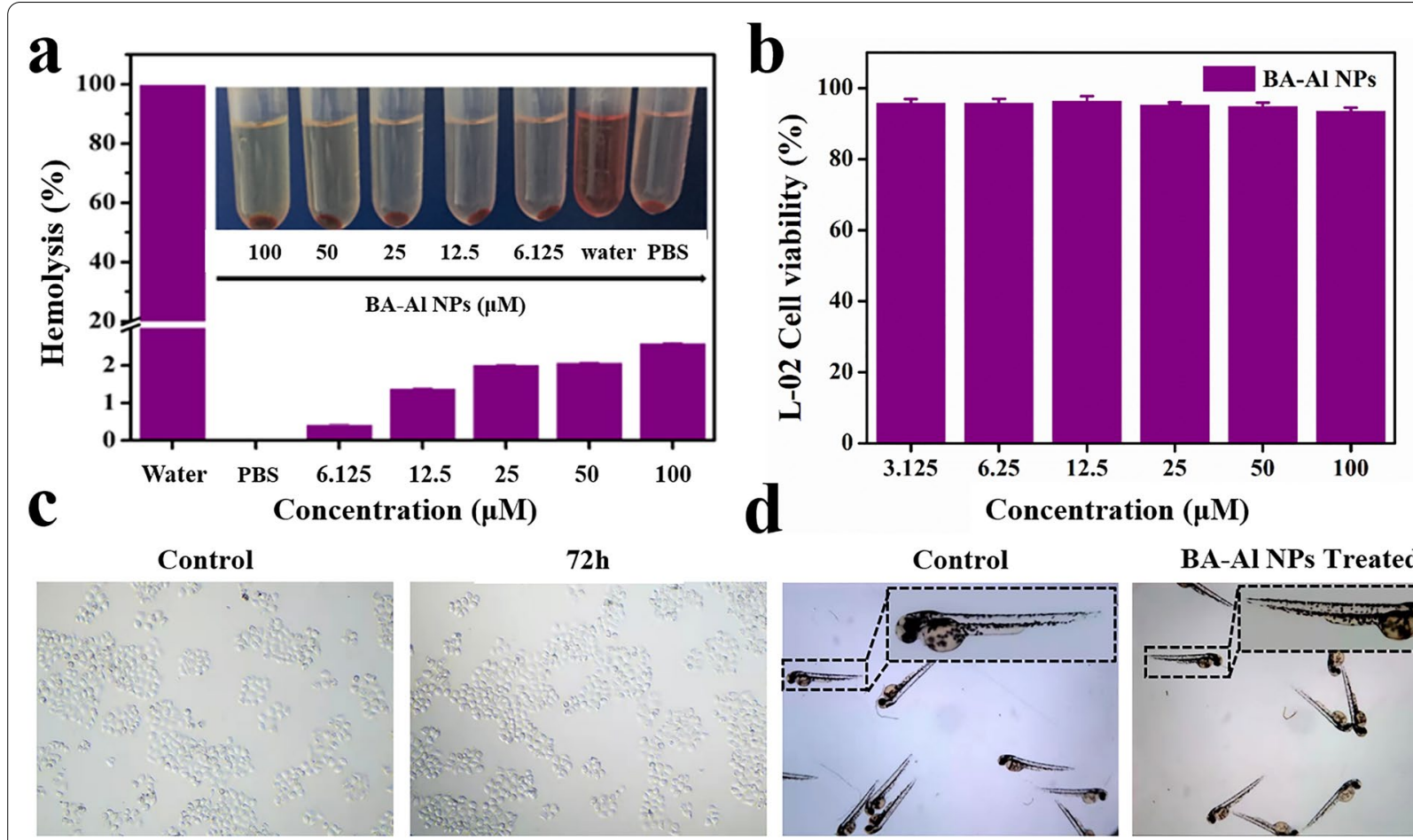

72h

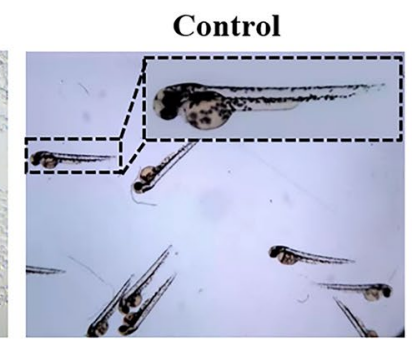

BA-Al NPs Treated
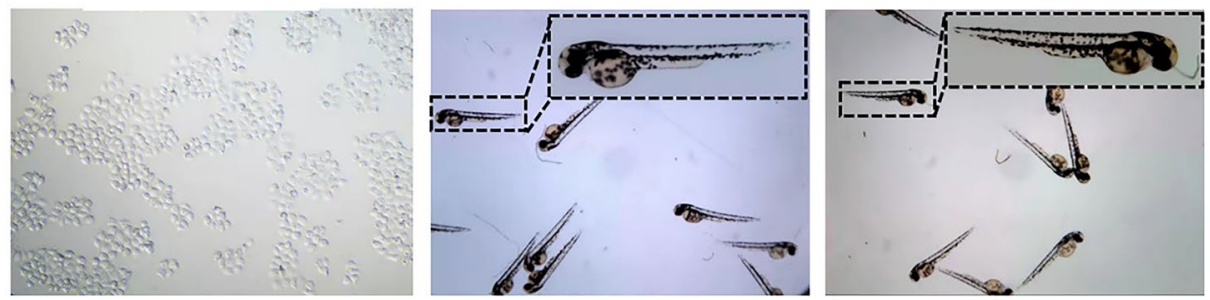

Fig. 7 Hemolysis assay of red blood cells treated with deionized water, PBS, and different concentrations of BA-Al NPs (a); Cell viability of L-02 cells incubated with BA-Al NPs for 72 h (b); Image of L-02 cells (c); Image of zebrafish of larvae treated with Holtfreter's solution and BA-AI NPs for 72 h (d)

and renal tubular cell cast. The oral free-form INS group showed glomerular atrophy, indicating that oral INS had no protective effect on the kidney of diabetic rats (Fig. 6d4). In addition, there is little tissue injury or infiltration could be observed in the organs of the SC INS and INS@BA-Al NPs group, indicating that SC INS and INS@BA-Al NPs has a protective effect on the kidney. In addition, compared with the control group, no significant pathological feature was founded in the liver and heart of the diabetic rats treated with INS@BA-Al NPs. These results also highlighted the superiority of BA-Al NPs as nanocarriers to delivery INS.

\section{Biosafety evaluation of BA-AI NPs}

As a newly discovered drug delivery carrier for oral administration, the biosafety of BA-Al NPs was of vital importance. The effective therapeutic dose of aluminum ions was still far less than the heavy metal guidelines of the United States Pharmacopoeia (50,000 $\mu \mathrm{g}$ /day) and experiments were used to prove its safety. Hemolysis assay, cell cytotoxicity test and zebrafish model were performed in vitro and in vivo respectively. Hemolytic assays result suggested that even the concentration of $\mathrm{BA}-\mathrm{Al}$
NPs as high as $100 \mu \mathrm{M}$, it had no obvious hemolytic activity in the rats' red blood cells (Fig. 7a). The hemolysis rate of BA-Al NPs was far lower than the internationally recognized standard (5\%), indicating its good biocompatibility. The result showed that BA-Al NPs had potential application in blood contact [47].

To further evaluate biosafety of BA-Al NPs, L-02, MIHA and HEK-293 T cells were carried out to test the cytotoxicity by an MTT assay [48]. As shown in Fig. 7b, $\mathrm{c}$ and Additional file 1: Fig. S3, cell viability of BA-Al NPs was over $90 \%$ even after incubated with BA-Al NPs at the highest concentration of $100 \mu \mathrm{M}$ for $72 \mathrm{~h}$, which revealed the BA-Al NPs had no adverse effect on L-02, MIHA and HEK-293 T cells.

Zebrafish can be used as an in vivo model to test biosafety due to its feasibility and high fecundity. We employed zebrafish to evaluate the biosafety of BA-Al NPs at the concentrations rang of $6.125-100 \mu \mathrm{M}$. In the experiment, healthy 1 - day old zebrafish larvae were cultured with BA-Al NPs for $72 \mathrm{~h}$. As shown in Fig. $7 d$, all zebrafish survived in both groups during the whole test, demonstrating BA-Al NPs had little toxicity on the growth of zebrafish larvae. All the results 
suggested that the BA-Al NPs had good biosafety and biocompatibility.

\section{Conclusion}

In this study, we explored distinctive self-assembled BA-Al NPs, which induced by coordination bonds and hydrogen bonds. To increase the bioavailability of INS, the advantages offered by BA-Al NPs are as follows: (i) The $\mathrm{pH}$-sensitivity of the nanoparticles ensured the stability of the drug under gastric acid conditions and released in the intestine; (ii) BA-Al NPs with gelatinous properties allowed for gradual and continuous release of insulin, which prolonged the residence time in intestine; (iii) BA-Al NPs disassembled and released BA to downregulate the $\mathrm{TJ}$ s proteins expression and further improve the absorption of INS to maintain glucose homeostasis through modulating TJs. In vivo pharmacological activity showed INS@BA-Al NPs could regulate blood glucose level and prolong circulation time. As a prospect, strategy of self-assembly nanoparticles fabricated by SMNPs could be a new field for INS delivery, and a variety of active SMNPs self-assembled with metal ions can be used to various drug delivery system for the good biocompatibility and effective treatment.

\section{Supplementary Information}

The online version contains supplementary material available at https://doi. org/10.1186/s12951-022-01260-9.

Additional file 1: Experiment methods. Materials; INS structural stability under different pH conditions; Molecular docking studies; Cell culture; In vitro toxicity assessment by cell viability; Hemolysis assay; Cytotoxicity evaluation by zebrafish assay; Table S1. Energy changes data for the interactions obtained from ITC. Table S2. Binding thermodynamics of AICl3 into BA. Table S3. Changes in body weight of rats treated with INS@ BA-AI NPs, oral INS solution, BA-AI NPs, NS and normal rats. Figure S1. (a-c) Far-UV CD spectra of INS for period of 36h. (d-f) Fluorescence spectra of INS for period of 36h. Figure S2. Morphology of BA-AI NPs. Figure S3. (a) Cell viability of MIHA cells incubated with BA-AI NPs for 72 h. (b) MIHA cells image of the control group and the $72 \mathrm{~h}$ group treated with BA-Al NPs for 72 h. (c) Cell viability of HEK-293T cells incubated with BA-AI NPs for $72 \mathrm{~h}$. (d) HEK-293T cells image of the control group and the $72 \mathrm{~h}$ group treated with BA-AI NPs for $72 \mathrm{~h}$

\section{Acknowledgements}

We thank that this research was supported by Beijing Nova program (No. Z201100006820026)

\section{Authors' contributions}

PW and $\mathrm{HL}$ designed the experiment and got the funding, and supervised the whole experiment process; PW, TM, BX guided the implementation of the experiment; $X J, Z Y, Y Y$, carried out all the experiments; $X J, Z Y, N H, X L, X L$ analyzed all data; $X J, Z Y$ wrote and revised the manuscript.

\section{Funding}

This research was funded by National Natural Science Foundation of China (No. 82073974 and No. 81603256), the Beijing Municipal Natural Science Foundation (No. 7202116), Beijing Nova program (No. Z201100006820026), project of China Association of Chinese Medicine (CACM-2018-QNRC2-B08), the Fundamental Research Funds for the Central Universities (2020-JYB-ZDGG-044,
BUCM-2019-JCRC002, and 2019-JYB-TD005, China), Beijing Key Laboratory for Basic and Development Research on Chinese Medicine (Beijing, 100102).

\section{Availability of data and materials}

All data generated or analysed during this study are included in this article and its additional file.

\section{Declarations}

Ethics approval and consent to participate

All of the animal experiments were provided by the Institutional Animal Care and Use Committee (IACUC) of Beijing University of Chinese Medicine (Beijing, (hina).

\section{Consent for publication}

All authors agreed to submit this manuscript.

\section{Competing interests}

The authors declare no competing financial interest. All authors agreed to submit this manuscript.

Received: 19 October 2021 Accepted: 12 January 2022

Published online: 05 March 2022

\section{References}

1. World Health Organization. Deafness and hearing loss, 9/3/2021. 2021. https://www.who.int/health-topics/hearing-loss\#tab=tab_2.

2. Ogurtsova K, da Rocha FJ, Huang Y, Linnenkamp U, Guariguata L, Cho N, Cavan D, Shaw J, Makaroff L. IDF Diabetes Atlas: global estimates for the prevalence of diabetes for 2015 and 2040. Diabetes Res Clin Pract. 2017;128:40-50.

3. Zhou X, Wu H, Long R, Wang S, Huang H, Xia Y, Wang P, Lei Y, Cai Y, Cai D, Liu Y. Oral delivery of insulin with intelligent glucose-responsive switch for blood glucose regulation. J Nanobiotechnol. 2020;18(1):96.

4. Xiao Y, Tang Z, Wang J, Liu C, Kong N, Farokhzad OC, Tao W. Oral insulin delivery platforms: strategies to address the biological barriers. Angew Chem Int Ed Engl. 2020;59(45):19787-95.

5. Easa N, Alany R, Carew M, Vangala A. A review of non-invasive insulin delivery systems for diabetes therapy in clinical trials over the past decade. Drug Discovery Today. 2018;11:010.

6. Shi S, Kong N, Feng C, Shajii A, Bejgrowicz C, Tao W, Farokhzad OC. Drug delivery strategies for the treatment of metabolic diseases. Adv Health Mater. 2019;8(12):e1801655.

7. Xiao YF, Tang ZM, Huang XG, Joseph J, Chen W, Liu C, Zhou J, Kong N, Joshi N, Du JZ, Tao W. Glucose-responsive oral insulin delivery platform for one treatment a day in diabetes. Matter. 2021;4(10):3269-85.

8. Seyam S, Nordin N, Alfatama M. Recent progress of chitosan and chitosan derivatives-based nanoparticles: pharmaceutical perspectives of oral insulin delivery. Pharmaceuticals (Basel, Switzerland). 2020;13(10):307.

9. Souto E, Souto S, Campos J, Severino P, Pashirova T, Zakharova L, Silva A, Durazzo A, Lucarini M, Izzo A, Santini A. Nanoparticle delivery systems in the treatment of diabetes complications. Molecules (Basel, Switzerland). 2019:24(43):4209.

10. Wong CY, Martinez J, Dass CR. Oral delivery of insulin for treatment of diabetes: status quo, challenges and opportunities. J Pharm Pharmacol. 2016;68(9):1093-108.

11. Zhong D, Zhang D, Chen W, He J, Ren C, Zhang X, Kong N, Tao W, Zhou M. Orally deliverable strategy based on microalgal biomass for intestinal disease treatment. Sci Adv. 2021;7(48):eabi9265.

12. Mumuni M, Kenechukwu F, Ofokansi K, Attama A, Díaz D. Insulin-loaded mucoadhesive nanoparticles based on mucin-chitosan complexes for oral delivery and diabetes treatment. Carbohydr Polymers. 2020;229:115506.

13. Tian H, He Z, Sun C, Yang C, Zhao P, Liu L, Leong K, Mao H, Liu Z, Chen Y. Uniform core-shell nanoparticles with thiolated hyaluronic acid coating to enhance oral delivery of insulin. Adv Healthcare Mater. 2018;7(17):1800285. 
14. Chaudhury A, Das S. Recent advancement of chitosan-based nanoparticles for oral controlled delivery of insulin and other therapeutic agents. AAPS PharmSciTech. 2011;12(1):10-20.

15. Hosseininasab S, Pashaei-Asl R, Khandaghi A, Nasrabadi H, NejatiKoshki K, Akbarzadeh A, Joo S, Hanifehpour Y, Davaran S. Synthesis, characterization, and in vitro studies of PLGA-PEG nanoparticles for oral insulin delivery. Chem Biol Drug Des. 2014;84(3):307-15.

16. Zhu S, Chen S, Gao Y, Guo F, Li F, Xie B, Zhou J, Zhong H. Enhanced oral bioavailability of insulin using PLGA nanoparticles co-modified with cell-penetrating peptides and Engrailed secretion peptide (Sec). Drug Delivery. 2016;23(6):1980-91.

17. Niu M, Lu Y, Hovgaard L, Guan P, Tan Y, Lian R, Qi J, Wu W. Hypoglycemic activity and oral bioavailability of insulin-loaded liposomes containing bile salts in rats: the effect of cholate type, particle size and administered dose. Eur J Pharm Biopharm. 2012;81(2):265-72.

18. Goldberg M, Gomez-Orellana I. Challenges for the oral delivery of macromolecules. Nat Rev Drug Discovery. 2003;2(4):289-95.

19. Fonte P, Araújo F, Silva C, Pereira C, Reis S, Santos H, Sarmento B. Polymer-based nanoparticles for oral insulin delivery: Revisited approaches. Biotechnol Adv. 2015;33(6):1342-54.

20. Newman DJ, Cragg GM. Natural products as sources of new drugs from 1981 to 2014. J Nat Prod. 2016;79(3):629-61.

21. Malhotra B, Kulkarni GT, Dhiman N, Joshi DD, Chander S, Kharkwal A, Sharma AK, Kharkwal H. Recent advances on Berberis aristata emphasizing berberine alkaloid including phytochemistry, pharmacology and drug delivery system. J Herbal Med. 2021;27:100433.

22. Zheng J, Fan R, Wu H, Yao H, Yan Y, Liu J, Ran L, Sun Z, Yi L, Dang L, et al. Directed self-assembly of herbal small molecules into sustained release hydrogels for treating neural inflammation. Nat Commun. 2019;10(1):1604.

23. Zhi KK, Sun Y, Zhao HT, Zhang CM, Peng HS, Yang X. Self-assembled supramolecular material derived from traditional Chinese medicine: injectable self-assembled natural product gel for drug delivery with biological activity. Mater Today Commun. 2020;23:101149.

24. Tian X, Wang P, Li T, Huang X, Guo W, Yang Y, Yan M, Zhang H, Cai D, Jia X, et al. Self-assembled natural phytochemicals for synergistically antibacterial application from the enlightenment of traditional Chinese medicine combination. Acta pharmaceutica Sinica B. 2020;10(9):1784-95.

25. Cheng J, Zhao H, Wang J, Han Y, Yang X. Bioactive natural small molecule-tuned coassembly of photosensitive drugs for highly efficient synergistic and enhanced type I photochemotherapy. ACS Appl Mater Interfaces. 2020;12(39):43488-500.

26. Li T, Wang PL, Guo WB, Huang XM, Tian XH, Wu GR, Xu B, Li FF, Yan C, Liang XJ, Lei HM. Natural berberine-based chinese herb medicine assembled nanostructures with modified antibacterial application. ACS Nano. 2019;13(6):6770-81.

27. Hisada M, Hiranuma M, Nakashima M, Goda N, Tenno T, Hiroaki H. High dose of baicalin or baicalein can reduce tight junction integrity by partly targeting the first PDZ domain of zonula occludens-1 (ZO-1). Eur J Pharmacol. 2020;887:173436.

28. Zhao Y, Chen F, Pan Y, Li Z, Xue X, Okeke C, Wang Y, Li C, Peng L, Wang $P$, et al. Nanodrug formed by coassembly of dual anticancer drugs to inhibit cancer cell drug resistance. ACS Appl Mater Interfaces. 2015;7(34):19295-305.

29. Xu HE, Wang TT, Yang CB, Li XL, Liu G, Yang ZM, Singh PK, Krishnan S, Ding D. Supramolecular nanofibers of curcumin for highly amplified radiosensitization of colorectal cancers to ionizing radiation. Adv Func Mater. 2018;28(14):1707140.

30. Davila YA, Sancho MI, Almandoz MC, Blanco SE. Structural and spectroscopic study of Al(III)-3-hydroxyflavone complex: Determination of the stability constants in water-methanol mixtures. Spectrochim Acta Part a-Mol Biomol Spectrosc. 2012;95:1-7.

31. Yu XD, Wang ZY, Li YJ, Geng LJ, Ren JJ, Feng GL. Fluorescent and electrochemical supramolecular coordination polymer hydrogels formed from ion-tuned self-assembly of small bis-terpyridine monomer. Inorg Chem. 2017;56(13):7512-8.

32. Dey M, Ghosh B, Giri T. Enhanced intestinal stability and $\mathrm{pH}$ sensitive release of quercetin in GIT through gellan gum hydrogels. Colloids Surfaces B Biointerfaces. 2020;196:111341.

33. Razani S, Tehrani AD. Development of new organic-inorganic, hybrid bionanocomposite from cellulose nanowhisker and Mg/Al-CO3-LDHfor enhanced dye removal. Int J Biol Macromol. 2019;133:892-901.
34. Memon AA, Arbab AA, Sahito IA, Mengal N, Sun KC, Qadir MB, Choi YS, Jeong $\mathrm{SH}$. Facile fabrication of activated charcoal decorated functionalized multiwalled carbon nanotube electro-catalyst for high performance quasi-solid state dye-sensitized solar cells. Electrochim Acta. 2017;234:53-62.

35. Bera H, Mothe S, Maiti S, Vanga S. Carboxymethyl fenugreek galactomannan-gellan gum-calcium silicate composite beads for glimepiride delivery. Int J Biol Macromol. 2018;107:604-14.

36. Jóźwiak K, Jezierska A, Panek J, Goremychkin E, Tolstoy P, Shenderovich I, Filarowski A. Inter- vs. intramolecular hydrogen bond patterns and proton dynamics in nitrophthalic acid associates. Molecules (Basel, Switzerland). 2020;25(20):4720

37. Sinha V, Chakma S. Synthesis and evaluation of CMC-g-AMPS/Fe/AI/AC composite hydrogel and their use in fluoride removal from aqueous solution. Environ Technol Innov. 2020;17:100620.

38. Ross P, Subramanian S. Thermodynamics of protein association reactions: forces contributing to stability. Biochemistry. 1981;20(11):3096-102.

39. Alibolandi M, Alabdollah F, Sadeghi F, Mohammadi M, Abnous K, Ramezani M, Hadizadeh F. Dextran-b-poly(lactide-co-glycolide) polymersome for oral delivery of insulin: in vitro and in vivo evaluation. J Controlled Release. 2016;227:58-70.

40. Wang WJ, Yan XM, Li QJ, Chen ZQ, Wang ZG, Hu HL. Adapted nanocarriers for gastrointestinal defense components: surface and challenges. Nanomed Nanotechnol Biol Med. 2020;29:102277.

41. Su FY, Lin KJ, Sonaje K, Wey SP, Yen TC, Ho YC, Panda N, Chuang EY, Maiti B, Sung HW. Protease inhibition and absorption enhancement by functional nanoparticles for effective oral insulin delivery. Biomaterials. 2012;33(9):2801-11.

42. Sun M, Hu HK, Sun LM, Fan Z. The application of biomacromolecules to improve oral absorption by enhanced intestinal permeability: a minireview. Chin Chem Lett. 2020;31(7):1729-36.

43. Wang D, Sun M, Zhang Y, Chen Z, Zang S, Li G, Li G, Clark A, Huang J, Si L. Enhanced therapeutic efficacy of a novel colon-specific nanosystem loading emodin on DSS-induced experimental colitis. Phytomed Int J Phytother Phytopharmacol. 2020;78:153293.

44. Adachi M, Inoko A, Hata M, Furuse K, Umeda K, Itoh M, Tsukita S. Normal establishment of epithelial tight junctions in mice and cultured cells lacking expression of ZO-3, a tight-junction MAGUK protein. Mol Cell Biol. 2006;26(23):9003-15.

45. Van Itallie C, Tietgens A, Anderson J. Visualizing the dynamic coupling of claudin strands to the actin cytoskeleton through ZO-1. Mol Biol Cell. 2017;28(4):524-34.

46. Mukhopadhyay P, Sarkar K, Bhattacharya S, Bhattacharyya A, Mishra R, Kundu P. pH sensitive N-succinyl chitosan grafted polyacrylamide hydrogel for oral insulin delivery. Carbohyd Polym. 2014;112:627-37.

47. Liang Y, Zhao X, Hu T, Chen B, Yin Z, Ma P, Guo B. Adhesive hemostatic conducting injectable composite hydrogels with sustained drug release and photothermal antibacterial activity to promote full-thickness skin regeneration during wound healing. Small. 2019;15(12):1900046.

48. Li F, Xing Q, Han Y, Li Y, Wang W, Perera T, Dai H. Ultrasonically assisted preparation of poly(acrylic acid)/calcium phosphate hybrid nanogels as $\mathrm{pH}$ responsive drug carriers. Mater Sci Eng C Mater Biol Appl. 2017;80:688-97.

\section{Publisher's Note}

Springer Nature remains neutral with regard to jurisdictional claims in published maps and institutional affiliations.

Ready to submit your research? Choose BMC and benefit from:

- fast, convenient online submission

- thorough peer review by experienced researchers in your field

- rapid publication on acceptance

- support for research data, including large and complex data types

- gold Open Access which fosters wider collaboration and increased citations

- maximum visibility for your research: over 100M website views per year

At BMC, research is always in progress.

Learn more biomedcentral.com/submissions 